\title{
Radiographic osteoarthrosis in the acromioclavicular joint resulting from manual work or exposure to vibration
}

\author{
B Stenlund, I Goldie, M Hagberg, C Hogstedt, O Marions
}

\begin{abstract}
The hypothesis that manual work and exposure to vibration are antecedents to the development of osteoarthrosis was assessed employing a cross sectional study design. The frequency of osteoarthrosis in the acromioclavicular joint was studied in three groups of workers in the construction industry. Two groups were manual workers ( 54 bricklayers and 55 rock blasters); the third group consisted of 98 foremen. The radiographic appearance of the right and left acromioclavicular joints was classified into one of five grades of osteoarthrosis. A protocol was developed to assess exposure on the basis of job title, years of manual work, total weight lifted during working life, and total hours of exposure to vibrating tools. Odds ratios for job titles (manual worker $v$ foreman) and for years of manual work as indicators of exposure were of similar magnitude of around $\mathbf{2 \cdot 5}$. Construction workers who had lifted more than 709 tonnes had an increased risk of developing severe osteoarthrosis of the right acromioclavicular joint, odds ratio: 2.62 ( $95 \%$ confidence interval $(95 \% \mathrm{CI})$, 1-13-6.06). The odds ratio for the left side was
\end{abstract}

The Construction Industry's Organisation for Working Environment, Safety, and Health, Electrum/216, S-164 40 Kista, Sweden

B Stenlund

Department of Orthopaedics, Karolinska Hospital, Stockholm, Sweden

I Goldie

Division of Environmental Physiology, National Institute of Occupational Health, Solna and the Department of Occupational Medicine, Karolinska Hospital, Stockholm, Sweden

$M$ Hagberg

Division of Occupational Medicine, National Institute of Occupational Health, Solna and the Department of Occupational Medicine, Karolinska Hospital, Stockholm, Sweden

C Hogstedt

Department of Radiology, Södersjukhuset, Stockholm, Sweden

O Marions
$7 \cdot 67(95 \% \mathrm{CI}, 2 \cdot 76-21 \cdot 34)$. In the analysis of vibration exposure, workers who had been highly exposed to vibration had an odds ratio of $1.99(95 \% \mathrm{CI}, 1.00-3.92)$ on the right side and $2 \cdot 20(95 \%$ CI, 1.07-4.56) on the left. This effect almost disappeared after simultaneous adjustment for manual work. Occupational and ergonomic factors, such as the sum of lifted tonnes during working life, job title, and the sum of years of manual work seem to be risk factors for osteoarthrosis of the acromioclavicular joint, whereas vibration alone was a weaker risk factor.

In several reports it is indicated that stress and strain in the working place are factors in the development of occupational shoulder disorders. ${ }^{1-3}$ Other reports have dealt with osteoarthrosis in different joints in relation to varying occupational conditions. ${ }^{4-6}$ The effect of vibration on bone and joints has been studied among workers using pneumatic tools ${ }^{7}$ and operators of chainsaws, ${ }^{8}$ and has been reviewed by Gemne and Saraste. ${ }^{9}$

Shoulder pain is a common complaint among workers in the construction industry. Some of the structures that are believed to be the origin of shoulder pain are the muscular insertions, the bursae, and the shoulder joints-that is, the humeroscapular joint, the acromioclavicular joint, and the sternoclavicular joint. The acromioclavicular joint is situated in close relation to the supraspinatus muscle and the subacromial bursa and both are commonly affected among construction industry workers. The question raised was if changes in the acromioclavicular joint could explain this shoulder pain and if an increased risk of such changes existed among construction industry workers.

Little has been published on the causes of acromioclavicular osteoarthrosis. DePalma ${ }^{10}$ studied the acromioclavicular joint from different aspects but not the osteoarthrosis of the acromioclavicular joint in relation to occupational stress.

The aim of the present investigation was to study the influence of manual work and the exposure to 
vibration from pneumatic tools on the development of osteoarthrosis in the acromioclavicular joint. Symptoms from effects on the shoulder muscles were also studied but these results will be reported separately.

\section{Study subjects}

The source population was construction industry workers in the Stockholm region. In the Swedish construction industry, bricklayers either lay bricks or spend periods plastering; they do not cast concrete. Rock blasters in Sweden drill holes both underground and on the surface. They charge dynamite and transport rocks. In tunnels they also trim the roof. Swedish construction foremen are engineers and not manual workers and are rarely recruited from this group. The foremen are supervisors on the construction site; they also work in offices that are often close to the workplace. The three groups thus represent different occupational work loads, although they have a common workplace.

Representatives from these study groups were identified and randomly selected from the local union files to make up 75 bricklayers, 75 rock blasters, and 110 foremen.

All subjects were invited to participate by letter and reminded by telephone the day before the investigation. Refusals were received from 19 bricklayers, 20 rock blasters, and 13 foremen, either because they did not wish to participate or because they lived in another part of the country or abroad. One bricklayer was excluded from the investigation because of language difficulties. One of the bricklayers had worked for $\mathbf{1 8}$ years as a foreman and for only two years as a bricklayer and was consequently categorised as foreman. Thus the persons under study finally comprised 54 bricklayers, 55 rock blasters, and 98 foremen.

Table 1 presents a summary of the background variables of the study subjects.

\section{Methods}

The investigation was conducted in two different parts-namely, exposure assessment and radiography.

\section{EXPOSURE ASSESSMENT}

A protocol was developed to record estimated load lifted during working life, exposure to vibration, years as bricklayer, years as rock blaster, years as foremen, smoking habits, dexterity, ethnic groups, citizenship, and age. A specially trained nurse interviewed the participants using this protocol. Exposure to load was registered on an annual basis. The workers do piecework and are therefore reasonably well aware of how many bricks they lay or how many lifts they do daily.

Exposure was analysed qualitatively and quantitatively on the basis of: (1) job title; (2) the sum of load lifted during working years; (3) years of manual work; (4) the sum of hours of exposure to vibration.

Load lifted was summarised on an annual basis. The participants calculated how many days they had worked each year, how many loads they had lifted a day, and the weight of the loads. All working tools were recorded separately. The weight of a brick and of the trowel and mortar together is $3.5 \mathrm{~kg}$. Rock blasters most frequently use a jackhammer which weighs $47 \cdot 2-50 \cdot 7 \mathrm{~kg}$ and is lifted with both hands several times an hour. Rock blasters also load rocks of different weights; and these loads were also taken into account although their weight was not easily estimated.

Load lifted was categorised into one of three classes: 0-709, 710-25 999, and more than 25999 tonnes. The limits 710 and 26000 tonnes were chosen since they represent the median values for the foremen and the labourers respectively. The value of 710 tonnes corresponds to about $19.7 \mathrm{~kg}$ per working hour for a person who has worked 225 days a year for 20 years at eight hours a day.

Years of manual work were categorised into 0-9 years, 10-28 years, and more than 28 years; 29 years was the median value for the bricklayers and the rock blasters together.

Exposure to vibration was reported in the protocol for each tool used, and expressed as hours of

Table 1 Background variables of three groups of construction industry workers

\begin{tabular}{|c|c|c|c|}
\hline Variables & $\begin{array}{l}\text { Bricklayers } \\
\text { No }(\%)\end{array}$ & $\begin{array}{l}\text { Rock blasters } \\
\text { No }(\%)\end{array}$ & $\begin{array}{l}\text { Foremen } \\
\text { No }(\%)\end{array}$ \\
\hline $\begin{array}{l}\text { Right handed } \\
\text { Left handed } \\
\text { Ambidextrous } \\
\text { Smokers } \\
\text { Non-smokers } \\
\text { Ex smokers } \\
\text { Swedish citizenship } \\
\text { Other citizenship } \\
\text { Caucasian }\end{array}$ & $\begin{aligned} 44(81 \cdot 5) \\
2(3 \cdot 7) \\
8(14 \cdot 8) \\
24(44 \cdot 4) \\
9(16 \cdot 7) \\
21(38 \cdot 9) \\
48(88 \cdot 9) \\
6(11 \cdot 1) \\
54(100)\end{aligned}$ & $\begin{array}{c}43(78 \cdot 2) \\
3(5 \cdot 5) \\
9(16 \cdot 4) \\
23(41 \cdot 8) \\
11(20) \\
21(38 \cdot 2) \\
50(90 \cdot 9) \\
5(9 \cdot 1) \\
55(100)\end{array}$ & $\begin{array}{l}83(84 \cdot 7) \\
1(1) \\
14(14 \cdot 3) \\
28(28 \cdot 6) \\
36(36 \cdot 7) \\
34(34 \cdot 7) \\
86(87 \cdot 8) \\
12(12 \cdot 2) \\
98(100)\end{array}$ \\
\hline Age (y; mean (SD), range) & $50 \cdot 2(11 \cdot 4) 26-68$ & $51.8(11 \cdot 6) 33-70$ & $45 \cdot 8(10 \cdot 2) 27-65$ \\
\hline
\end{tabular}


exposure. The reported hours were then multipled by 1,10 , and 100 depending on which tool had been used. These exponents correspond to the three steps of energy emission from the vibrating tools suggested by Gemne and Saraste. ${ }^{9}$ The workers were then classified into one of three categories-namely, exposed to 0-9000 hours, 9001-225 200 hours, and more than 255200 hours. The limits represent the median values for foremen and rock blasters respectively.

The exposure variables were related to osteoarthrosis in the calculations of age standardised odds ratios as estimates of the relative risk.

The age distribution of the population was 26-70 years. The mean was 50.2 for the bricklayers, 51.8 for the rock blasters, and $\mathbf{4 5 . 8}$ for the foremen. (table 1 ) The influence of differences in the age distribution between the three groups was taken care of by stratification.

\section{RADIOGRAPHY}

Radiographic anteroposterior views of the right and left acromioclavicular joints were obtained. The films were viewed and approved by a radiologist (OM). The radiographs were then categorised by the radiologist and an orthopedic surgeon (BS) into one of five grades of osteoarthrosis according to Collins. ${ }^{11}$ The correlation of this morphological grading with the radiographic findings was previously investigated by Stenlund $e t a l^{12}$ and the radiographs were classified in accordance with this. The grading was grade 0 , normal; grade 1, minimal changes; grade 2, moderate changes, more severe changes occur in the cartilage and the bone structure begins to be affected; grade 3, severe osteoarthrosis; grade 4, totally destroyed joint.

Classification was achieved without knowledge of age, name, or exposure of the investigated person. For the calculations grades 2 and 3 were combined as osteoarthrosis. There were no joints found of grade 4. Joints of grades 0 and 1 were both considered normal, as the minimal changes of grade 1 would not have been considered as radiographically cerified osteoarthrosis in clinical practice.

\section{INTERACTION ANALYSIS}

Several of the exposure variables were fitted into multiple regression models. Each model included the variables age (in groups of $25-49,40-55$, and 56-70 years), smoking habits (non-smoker or previous and current smoker), and dexterity. Dexterity was categorised as right handed or left handed and ambidextrous, as there were few left handed men and most of those who were ambidextrous had been left handed as children.

The exposure variables in the regression model were job category, load lifted, years of manual work, and vibration and were included separately. Load lifted, vibration, and manual years were fitted into the models in the categories previously described. The job categories considered were bricklayer, rock

Table 2 Unconditional multiple logistic regression of osteoarthrosis of the left and right acromioclavicular joint

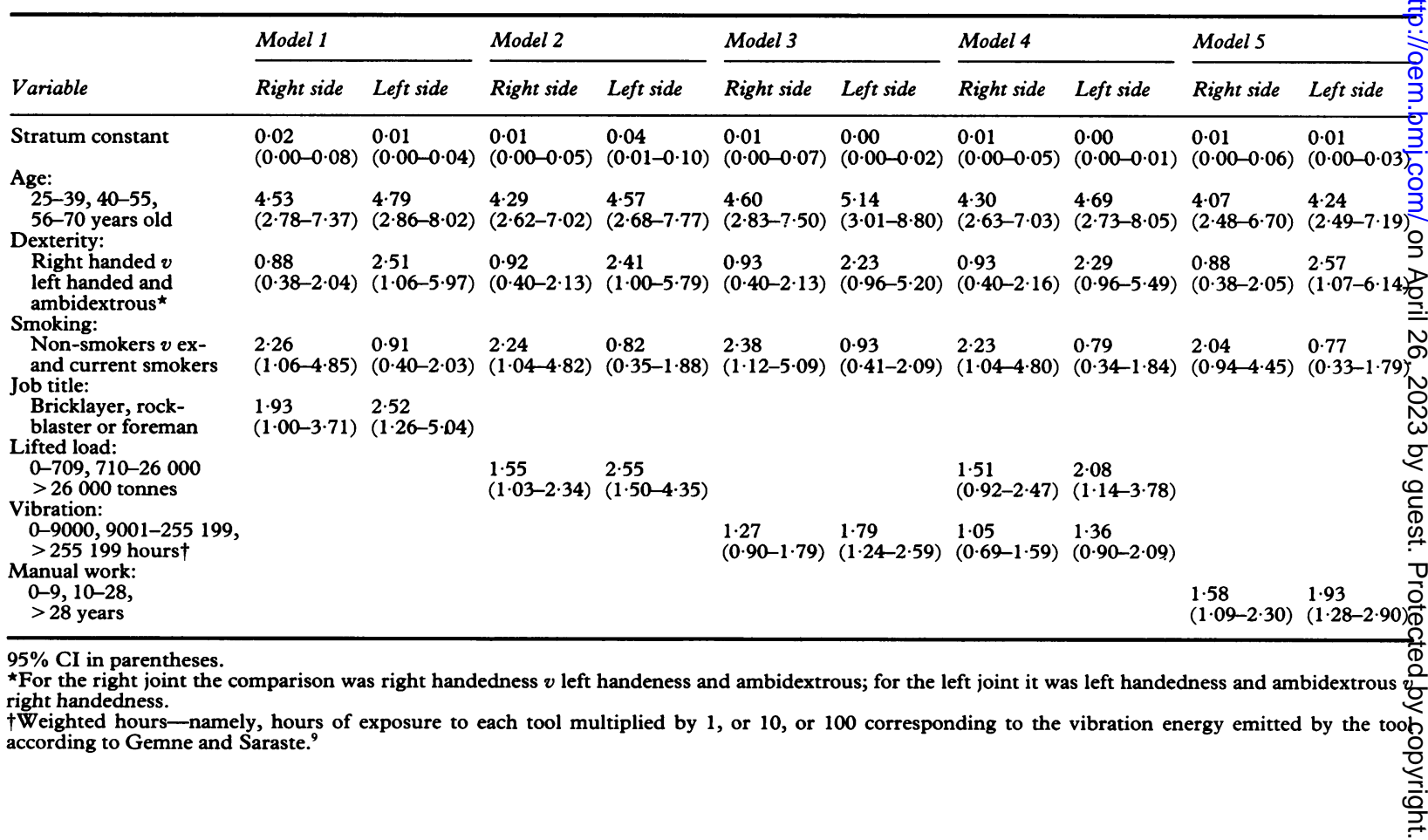


Table 3 Distribution of exposure factors and of osteoarthrosis in the acromioclavicular joint in three groups of construction workers

\begin{tabular}{|c|c|c|c|}
\hline & $\begin{array}{l}\text { Bricklayers } \\
\text { Mean }(S D)\end{array}$ & $\begin{array}{l}\text { Rock blasters } \\
\text { Mean }(S D)\end{array}$ & $\begin{array}{l}\text { Foremen } \\
\text { Mean }(S D)\end{array}$ \\
\hline $\begin{array}{l}\text { Years of work in the profession } \\
\text { Tonnes lifted during working life } \\
\text { Weighted levels of hours of exposure to vibrations }\end{array}$ & $\begin{array}{l}28 \cdot 0(10 \cdot 6) \\
29437(18580 \cdot 6) \\
74705(154816)\end{array}$ & $\begin{array}{l}22 \cdot 8(10 \cdot 8) \\
33210(23572 \cdot 2) \\
1098300(1116970)\end{array}$ & $\begin{array}{l}19 \cdot 6(9 \cdot 9) \\
2261(3975 \cdot 4) \\
57031(169067)\end{array}$ \\
\hline \multicolumn{4}{|l|}{$\begin{array}{l}\text { Osteoarthrosis of grade 2-3: } \\
\text { Comparative frequencies }\end{array}$} \\
\hline $\begin{array}{l}\text { right side } \\
\text { left side }\end{array}$ & $\begin{array}{l}59 \cdot 3 \\
40 \cdot 7\end{array}$ & $\begin{array}{l}61 \cdot 8 \\
56 \cdot 4\end{array}$ & $\begin{array}{l}36 \cdot 7 \\
23 \cdot 4\end{array}$ \\
\hline
\end{tabular}

${ }^{\star}$ Hours of exposure to each tool multiplied by 1,10 , and 100 corresponding to the vibration energy level of the tool.

blaster, or foreman. In one model-table 2, model 4-vibration and exposure to lifted load acted simultaneously.

The data were analysed as age stratified MantelHaenszel odds ratios with $95 \%$ confidence intervals $(95 \% \mathrm{CIs}){ }^{13}$ using the epidemiological computer program QUEST. The interaction analyses were performed using unconditional logistic regression models and the Epilog computer program.

The background variables are presented as means with standard deviation (SD).

\section{Results}

Among foremen the relative frequency of osteroarthrosis of grade 2 and 3 was $36.7 \%$ on the right side and $23.4 \%$ on the left side. The corresponding figures for the bricklayers were $59.3 \%$ on the right side and $40.7 \%$ on the left side. Among the rock blasters $61.8 \%$ had osteoarthrosis of grade 2 and 3 on the right side, whereas $56.4 \%$ had osteoarthrosis of the same magnitude on the left side (table 3 ).

The age adjusted odds ratio for osteoarthrosis in the right acromioclavicular joint for bricklayers and rock blasters as compared with foremen, was 2.16 on the right and 2.56 on the left side (table 4).
The odds ratios for osteoarthrosis for those reporting more than 28 years of manual work compared with those reporting less than 10 years was 2.91 on the right side and 2.46 on the left (table 4). A comparison of less than 10 years with $10-28$ years gave an odds ratio of 2.23 on the right side and 2.32 on the left side.

\section{LIFTED LOAD AND VIBRATION}

Estimated lifted load varied between 0 and 123082 tonnes. Bricklayers had lifted a mean of 29437 tonnes and rock blasters a mean of 33210 tonnes whereas foremen had lifted a mean of 2261 tonnes (table 3).

For workers who had lifted 710-25999 tonnes compared with less than 710 tonnes the odds ratio of the right side was $2 \cdot 28$ and the corresponding odds ratio for the left side was 7.29. In a comparison of those who had lifted more than 25999 tonnes with those who had lifted less than 710 tonnes the odds ratios were 3.18 on the right side and 10.34 on the left side (table 4).

Exposure to a weighted level of 9001-255 200 hours of vibrations gave an odds ratio of $2 \cdot 16$ on the left side and 1.13 on the right side. The risk increased with length of exposure (table 4).

Table 4 Risk factor analysis for osteoarthrosis of the acromioclavicular joint in relation to exposure variables, standardised to age $(25-39,40-55$, and $56-70$ years old)

\begin{tabular}{|c|c|c|c|c|}
\hline Variables & Odds ratio right side & $95 \% C I$ & Odds ratio left side & $95 \% C I$ \\
\hline $\begin{array}{l}\text { Job title: } \\
\text { Bricklayers and rock blasters } v \text { foremen } \\
\text { Bricklayers } v \text { foremen } \\
\text { Rock blasters } v \text { foremen }\end{array}$ & $\begin{array}{l}2 \cdot 16 \\
2 \cdot 21 \\
2 \cdot 13\end{array}$ & $\begin{array}{l}1 \cdot 14-4.09 \\
1 \cdot 03-4.72 \\
0.98-4.64\end{array}$ & $\begin{array}{l}2 \cdot 56 \\
1 \cdot 82 \\
4 \cdot 03\end{array}$ & $\begin{array}{l}1 \cdot 33-4.93 \\
0 \cdot 84-3.94 \\
1 \cdot 77-9 \cdot 20\end{array}$ \\
\hline $\begin{array}{l}\text { Years of manual work: } \\
>28 \text { years } v<10 \text { years } \\
10-28 \text { years } v<10 \text { years }\end{array}$ & $\begin{array}{l}2 \cdot 91 \\
2 \cdot 23\end{array}$ & $\begin{array}{l}1 \cdot 15-7.35 \\
1.06-4.69\end{array}$ & $\begin{array}{l}2 \cdot 46 \\
2 \cdot 32\end{array}$ & $\begin{array}{l}1 \cdot 01-5 \cdot 97 \\
1 \cdot 02-5 \cdot 25\end{array}$ \\
\hline $\begin{array}{l}\text { Load lifted: } \\
710-25999 \text { tonnes } v<710 \text { tonnes } \\
>25000 \text { tonnes } v<710 \text { tonnes }\end{array}$ & $\begin{array}{l}2 \cdot 28 \\
3 \cdot 18\end{array}$ & $\begin{array}{l}0.97-5 \cdot 39 \\
1.09-9 \cdot 24\end{array}$ & $\begin{array}{r}7 \cdot 29 \\
10 \cdot 34\end{array}$ & $\begin{array}{l}2 \cdot 49-21 \cdot 34 \\
3 \cdot 10-34 \cdot 46\end{array}$ \\
\hline $\begin{array}{l}\text { Vibration: } \\
9001-255200 \text { hours }^{\star} v<9001 \text { hours } \\
>255200 \text { hours } v<9001 \text { hours }\end{array}$ & $\begin{array}{l}1 \cdot 13 \\
2 \cdot 18\end{array}$ & $\begin{array}{l}0.53-2.40 \\
1.04-4.56\end{array}$ & $\begin{array}{l}2 \cdot 16 \\
3 \cdot 13\end{array}$ & $\begin{array}{l}1 \cdot 00-4 \cdot 68 \\
1 \cdot 40-6.99\end{array}$ \\
\hline
\end{tabular}

*Weighted hours - namely, hours of exposure to each tool multiplied by 1, 10, or 100 corresponding to the vibration energy emitted by the tool according to Gemne and Saraste. 
Table 5 Distribution of osteoarthrosis in relation to job title and dexterity

\begin{tabular}{|c|c|c|c|c|c|c|c|c|c|c|c|c|}
\hline & \multicolumn{12}{|c|}{ No with (yes) or without (no) osteoarthrosis } \\
\hline & \multicolumn{6}{|c|}{ Right side } & \multicolumn{6}{|c|}{ Left side } \\
\hline & \multicolumn{2}{|c|}{ Bricklayers } & \multicolumn{2}{|c|}{ Rock blasters } & \multicolumn{2}{|c|}{ Foremen } & \multicolumn{2}{|c|}{ Bricklayers } & \multicolumn{2}{|c|}{ Rock blasters } & \multicolumn{2}{|c|}{ Foremen } \\
\hline & Yes & No & Yes & No & Yes & No & Yes & No & Yes & No & Yes & No \\
\hline \multirow{2}{*}{$\begin{array}{l}\text { Dexterity: } \\
\text { Right handed } \\
\text { Left handed or ambidextrous }\end{array}$} & & & & & & & & & & & & \\
\hline & 26 & 18 & 27 & 16 & 29 & 54 & 16 & 28 & 23 & 20 & 18 & 65 \\
\hline
\end{tabular}

EXPOSURE RESPONSE

In several of the analyses an exposure response relation was indicated. The high groups gave higher odds ratios compared with medium groups (table 4).

Table 5 gives the distribution of acromioclavicular joints affected by osteoarthrosis in relation to dexterity and job title.

\section{INTERACTION: RESULTS OF THE MULTIPLE REGRESSION} ANALYSIS

In the logistic regression analysis smoking was associated with odds ratios of $2 \cdot 04-2 \cdot 38$ for osteoarthrosis on the right side but had no influence on the left side. Smoking habits were included in all regression models, however, and cannot explain the influence of different measures of load (table 2).

In most models, left handedness gave an odds ratio of about 2.5 for osteoarthrosis of the left side. Right handedness did not appear to influence the osteoarthrotic process on the right side.

The exposure parameters that reflected manual work (job title, sum of load lifted during working years, years of manual work) gave odds ratios and $95 \%$ CIs that indicated a truly raised risk.

In one model (model 4) in which exposure to vibration and load lifted were entered simultaneously, the apparent effect of vibration on the risk for osteoarthrosis was reduced to an odds ratio of 1.05 for the right side and 1.36 for the left side. The ratio for the influence of lifted load was also reduced in this analysis (table 2, model 4).

\section{Discussion}

A striking feature of this study was the high prevalence of acromioclavicular osteoarthrosis in the bricklayers and rock blasters and comparatively low prevalence in the foremen. Parameters of exposure such as tonnes lifted during working life and years of manual work had a significant effect.

\section{SELECTION BIAS}

A selection bias that may influence the outcome is the possibility that the issue under study, osteoarthrosis of the acromioclavicular joint, makes it impossible to work as a bricklayer or rock blaster but does not influence work as a foreman to an equivalent degree. This would lead to an underestimation of the relative risk, as there would be fewer bricklayers and rock blasters with severe osteoarthrosis available for the study. Such selection presupposes that osteoarthrosis of the acromioclavicular joint always impairs the function, a supposition that clinical practice, however, does not support. In a longitudinal study the estimation of the relative risk could have been made with higher precision, but such a study demands large resources.

\section{MISCLASSIFICATION OF EXPOSURE}

Non-differential misclassification diminishes any truly increased risk. ${ }^{14}$ In our study, non-differential misclassification might have been introduced by the use of subjective assessment of exposure. Kilbom $e t$ $a l^{15}$ showed that $20 \%$ of self reported lifts did not occur in the workplace and the only $10 \%$ of the workers reported correct weights and frequencies of material handled. In the present study, the use of many different exposure variables was one way of minimising any subjective influence on estimations of occupational stress. Another was to classify the exposure parameters in broad groups so that the exact values played a less prominent part. Yet another potential source of non-differential misclassification was the absence of a latency period in the calculations; however, as exposure varied only slightly during the exposure period, the influence of this source would have been small. Age can result in a differentialmisclassification of assessment of exposure based upon the premise that older people in general have more difficulties in recalling exposure than younger people. This would also diminish a truly increased risk.

\section{MISCLASSIFICATION OF OUTCOME}

Osteoarthrosis of the acromioclavicular joint was classified according to Collins ${ }^{11}$ into one of five different grades. In the calculations, grades 0 and 1 were combined as no osteoarthrosis and grades 2 and 3 were combined as true osteoarthrosis. The difference between grades 1 and 2 is fairly distinct. To minimise risk of misclassification, all radiographs were graded by two of the authors in one session. 
CONFOUNDING

Age, smoking habits, and dexterity, which are possible confounders, were included in the multiple regression analysis. Age was found to be a true confounder and treated as such by age standardisation.

Age alone was the strongest factor that influenced the development of osteoarthrosis in the acromioclavicular joint. This was found in all analyses and in the logistic regression analysis in which age had the strongest influence on the osteoarthrosis outcome in all models. The different influence of smoking on the osteoarthrosis of the right side and the left side has no rational explanation. Smoking was treated as a confounder in the interaction analyses but not in the other analyses.

The groups were chosen initially to contrast heavy work with light work in the same working environment. Bricklayers work with equal loads in each hand and rock blasters also lift their tools and material with both hands. Thus, dexterity may have little significance in these situations, but was treated as a confounder in the interaction analyses.

In the analysis of lifted load, the left joint appeared to be more susceptible to osteoarthrotic changes than the right. The finding that left handedness was associated with an increased risk and right handedness was not might indicate that the left side is more susceptible to osteoarthrosis but can also be explained by the fact that only $15 \%$ of the foremen were left handed or ambidextrous whereas $21 \%$ of the bricklayers and rock blasters fell into the same category (table 5).

\section{EXTERNAL VALIDITY}

In a recent thesis Vingård has shown an increased risk of osteoarthrosis of the hip among those who have been exposed to heavy work. The hip joint is of a type entirely different from the acromioclavicular joint but the study indicates, with good precision, a relation between heavy loading and the development of osteoarthrosis of a joint. In this respect our finding also indicated an association.

Experimental evidence exists to show that vibration plays a part in the development of osteoarthrosis $^{16}$ but this has no strong support from clinical or epidemiological studies. ${ }^{9}$ Our finding that exposure to more than 9000 hours of vibration increased the risk odds ratios of osteoarthrosis in the left and right joints seemed to support the idea that vibration influences the development of acromioclavicular osteoarthrosis, although the estimated odds ratio for the right side was uncertain (95\% CI, 0.80-2.86). Furthermore, exposure to vibration was always associated with manual work, and when the two factors were added simultaneously in the multiple logistic regression analysis, the association with vibration was weaker and had low precision (table 2 , model 4).

Because the influence of lifted load was also reduced in this analysis, the two exposures, vibration and lifted load, may both contribute to the development of osteoarthrosis.

\section{Conclusions}

Occupational factors, such as the sum of tonnes lifted during working life, job title, and the sum of years of manual work, seemed to be risk indicators of osteoarthrosis in the acromioclavicular joint, whereas vibration alone seemed to be a weaker factor.

This study was supported by grants from the Swedish Labour Market Insurance Company, AFA, and the Research Foundation of Bygghälsan. We want to thank Barbro Olofsson and Staffan Norlander for their help with data collection. We are also grateful for the generous cooperation of the staff at the Radiological Department of Södersjukhuset in Stockholm.

Requests for reprints to: Berndt Stenlund, Bygghälsan, Electrum/216, S-164 40 Kista, Sweden.

1 Bjelle A, Hagberg M, Michaelson G. Clinical and ergonomic factors in prolonged shoulder pain among industrial workers. Scand $J$ Work Environ Health 1979;5:205-10.

2 Hagberg M, Wegman DH. Prevalence rates and odds ratios of shoulder-neck diseases in different occupational groups. $\mathrm{Br} J$ Ind Med 1987;44:602-10.

3 Herberts P, Kadefors R, Högfors C, Sigholm G. Shoulder pain and heavy manual labour. Clin Orthop 1984;191:168-78.

4 Anderson JA. Arthrosis and its relation to work. Scand $J$ Work Environ Health 1984;10:429-33.

5 Mintz G, Fraga A. Severe osteoarthrosis of the elbow in foundry workers. Arch Environ Health 1973;27:78-80.

6 Vingaird E. Work, sports, overweight and osteoarthrosis of the hip. Epidemiological studies. Arbete och Hälsa 1991;25:1-59.

7 Rostoch P. Gelänkschäden durch Arbeiten mit Pressluftwerkzeugen und andere schwere körperlich Arbeit. Medizinische Klinik. Wochenschrift für praktische Arzte. 1936;11:341-3.

8 Horvath von F, Kakosy T. Arthrose des distalen radioulnaren Gelenkes bei Motorsägenbetreibern. Fortschritte auf Dem Gebiete Der Röntgenstrahlen und der Nuclearmedizin 1979;131:54-9

9 Gemne G, Saraste H. Bone and joint pathology in workers using hand-held vibrating tools. An overview. Scand $J$ Work Environ Health 1987;13:290-300.

10 De Palma AF. Degenerative changes in the sternoclavicular and acromioclavicular joints in various decades. Springfield, Il: C C Thomas, 1957.

11 Collins DH. The pathology of articular and spinal diseases. Liverpool: Edward Arnold and Co, 1950:74-103.

12 Stenlund B, Marions O, Engström KF, Goldie I. Correlation of macroscopic osteoarthrotic changes and radiographic findings in the acromioclavicular joint. Acta Radiologica Diagnosis 1988;29:571-6.

13 Mantel N, Haenszel W. Statistical aspects of the analysis of data from retrospective studies of disease. J Natl Cancer Inst $1959 ; 22: 719-48$.

14 Flegal KM, Brownie C, Haas JD. The effects of exposure misclassification on estimates of the relative risk. $A m \mathrm{~J}$ Epidemiol 1986;123:736-51.

15 Kilbom $\AA$, Liew M, Lagerlöf E, Broberg E. An ergonomic study of notified cases of occupational musculoskeletal disease. Arbete och Hälsa 1984;45:1-51.

16 Radin EL, Parker HG, Pugh JW, Steinberg RS, Paul IL, Rose RM. Response of joints to impact loading-III. J Biomech 1973;6:51-7.

Accepted 18 November 1991. 